\title{
Pentacam Anterior Float Anomaly Due to Band Shaped Keratopathy
}

\author{
Sudarshan Kumar Khokhar ${ }^{1}$, Amber Amar Bhayana ${ }^{*}$, Priyanka Prasad ${ }^{1}$ \\ ${ }^{1}$ Dr. RP Centre for Ophthalmic Sciences, AIIMS, New Delhi, India
}

*Corresponding Author: Amber Amar Bhayana, Senior Resident, Dr. Rajendra Prasad Centre for Ophthalmic Sciences, All India Institute of Medical Sciences, New Delhi, India; Email: amber.amar.bhayana@gmail.com

Received Date: 05-01-2021; Accepted Date: 24-01-2021; Published Date: 31-01-2021

Copyright $^{\odot} 2021$ by Bhayana AA, et al. All rights reserved. This is an open access article distributed under the terms of the Creative Commons Attribution License, which permits unrestricted use, distribution, and reproduction in any medium, provided the original author and source are credited.

\section{Clinical Image}

A 27 year old female with best corrected visual acuity 20/60 and 20/30 in the right (OD) and left (OS) eyes respectively presented to us for refractive surgery. Refractive errors were -9.25 $\mathrm{D}$ and $-7 \mathrm{D}$ spherical equivalent OD and OS respectively. She had undergone scleral buckling for OD rhegmatogenous retinal detachment 4 years back. On examination OS was normal. OD had band shaped keratopathy in the cornea near inferotemporal and inferonasal limbus (Fig. 1). Posterior segment OD showed attached retina with buckle indent and cryopexy scarring (Fig. 1). Pentacam OD showed red area in the front float elevation difference on Belin Ambrosio enhanced ectasia display map (Fig 1). The patient was started on lubricants for corneal surface treatment before planning for refractive surgery.

Band shaped keratopathy is a corneal degeneration commonly band shaped which involves deposition of calcium in the sub-epithelium, Bowman's layer and anterior corneal stroma [1]. Common causes of the degeneration include chronic ocular diseases like uveitis, chemical exposure to cornea, autoimmune diseases, systemic diseases causing hypercalcemia, intraocular surgeries etc. Scleral buckling has been reported to cause calcific band keratopathy [2]. In our case the keratopathy could have been due to scleral buckling, any corneal intervention during the buckling procedure like paracentesis or due to the rhegmatogenous retinal detachment and its inflammatory sequelae itself. Another cause could be preservatives used in topical medications for post-operative period $[3,4]$. Due to corneal surface irregularities caused, BSK are bound to cause tear film stasis abnormality and ocular surface disease which is manifested as a red area in the BAD map [5]. 

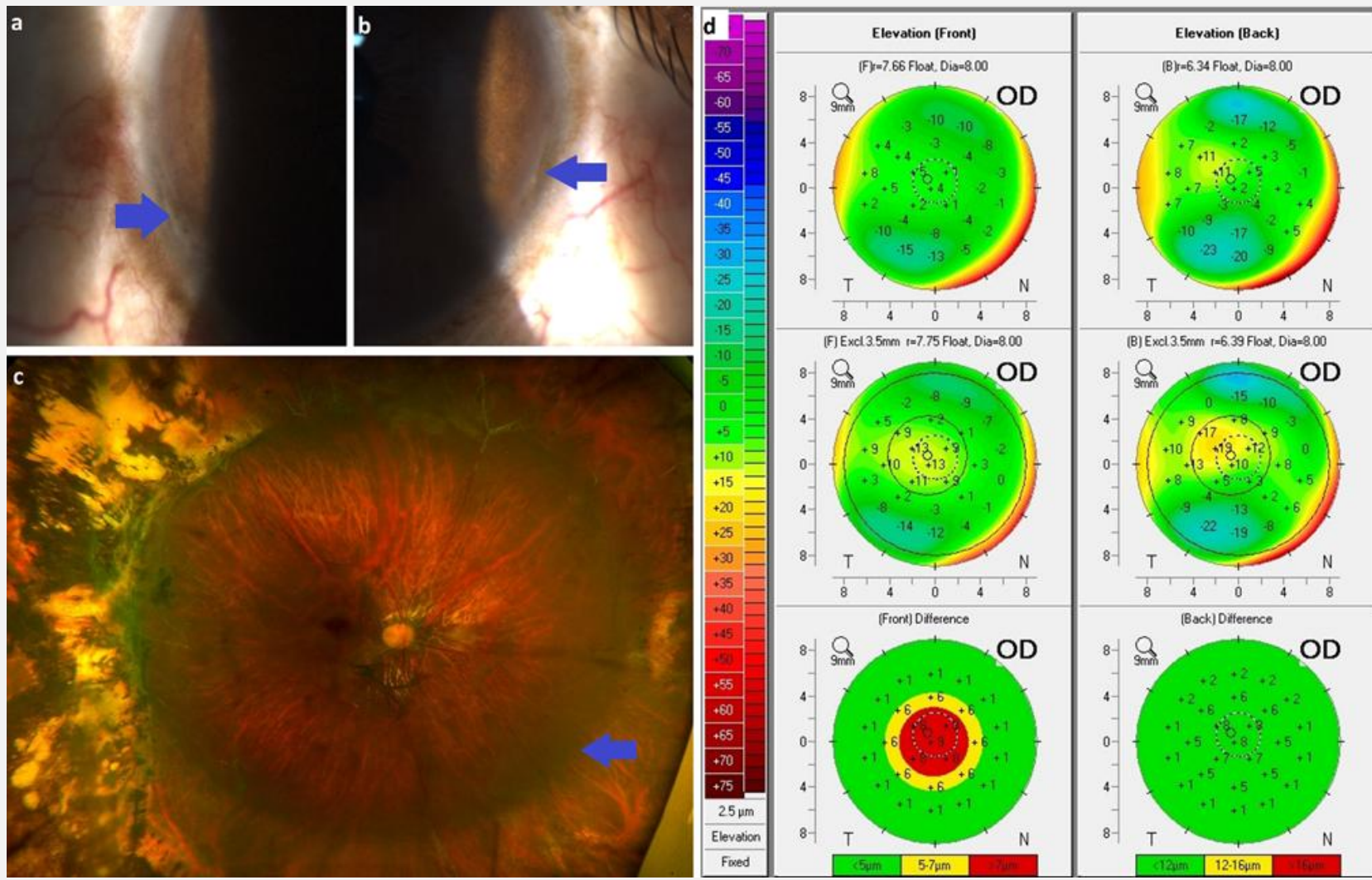

Figure 1: (a,b) Slit lamp photograph showing inferotemporal (a) Inferonasal (b) Band shaped keratopathy 4 sample readings of refractive error through intraoperative aberrometry. (c) Posterior segment photograph showing post scleral buckling attached retina. (d) Belin Ambrosio enhanced ectasia display showing red on anterior elevation difference map.

\section{References}

1. Jhanji V, Rapuano CJ, Vajpayee RB. Corneal calcific band keratopathy. Curr Opin Ophthalmol. 2011;22(4):283-9.

2. Sen P, Agarwal A, Bhende P, Gopal L. Surgical outcomes of vitreoretinal surgery for rhegmatogenous retinal detachment in eyes with regressed retinopathy of prematurity. Indian J Ophthalmol. 2019;67:896-902.

3. Pavicić-Astalos J, Lacmanović-Loncar V, Petric-Vicković I, Sarić D, Mandić Z, Csik T, et al. Eye drops preservative as the cause of corneal band keratopathy in long-term pilocarpine hydrochloride treatment. Acta Clin Croat. 2012;51(1):107-11.

4. Schlötzer-Schrehardt U, Zagórski Z, Holbach LM, Hofmann-Rummelt C, Naumann GOH. Corneal stromal calcification after topical steroid-phosphate therapy. Arch Ophthalmol. 1999;117(10):1414-8.

5. Belin MW, Ambrósio R. Scheimpflug imaging for keratoconus and ecstatic disease. Indian J Ophthalmic. 2013;61(8):401-6.

Khokhar SK| Volume 2; Issue 1 (2021) | JOAR-2(1)-007 | Clinical Image

Citation: Bhayana AA, et al. Pentacam Anterior Float Anomaly Due to Band Shaped Keratopathy. J

Ophthalmol Adv Res. 2021;2(1):1-2.

DOI: http://dx.doi.org/10.46889/JOAR.2021.2102 